This report was prepared as an account of work sponsored by the United States Government. Neither the United States nor the United States Atomic Energy Commission, nor any of their employees, nor any of their contractors, subcontractors, or their employees, makes any warranty, express or implied, or assumes any legal liability or responsibility for the accuracy, completeness or usefuiness of any information, apperatus, product or process disclosed, or represents that its use would not infringe privately owned rights.

In the interest of prompt distribution, this LAMS report was not edited by the Technical Information staff.

Printed in the United States of America. Available from National Technical Information Service

U. S. Department of Commerce 5285 Port Royal Road Springfield, Virginia 22151

Price: Printed Copy \$3.00; Microfiche \$0.95 


\author{
LA.5075-MS \\ Informal Report \\ UC-28 \\ ISSUED: November 1972
}

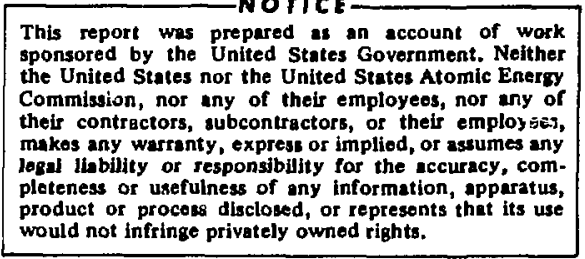

\title{
Computation of Magnetic End Fields, and Comparison with Measurement
}

by

H. F. Vogel

R. J. Lari*

*Argonne National Laboratory 
COMPUTATION OF MAGNETIC END FIELDS, AND COMPARISON WITH MEASUREMENT

by

H. F. Vogel and R. J. Lari

ABSTRACT

The dependence of the magnetic effective length and the fringefield correction constant on the central field flux density are of particu.ar interest in designing beam transport systems. It is therefore important to know the accuracy with which they may be calcilated. Measurements on Argonne's bending magnet BM-111 have been compared with TRIM computations. The agreement between computed and measured effective lengths was within 1.7 percent in pole separa tion units for flelds from 0 to $17 \mathrm{kG}$. The agreement between coirputed and measured fringe field correction constant, which determines the correction angle to the transverse focal length, was within 0.56 percent of the measured value of $8 \mathrm{kG}$.

\section{MAGNET GEOMETRY}

Flgure 1 shows an oblique sectional view of the ANL, BM-111 bending magnet. Since TRIM is a twodimenstonal program and $1 \mathrm{t}$ is destred to calculate the field in the $Y Z$ plane, an additional steel yoke must be used to return the flux from the pole to the midplane. This is shown in Fig. 2 as that steel having a permeability of $10^{9}$. This additional yoke limits the universe and is arranged so its effect on the field in the region of interest is small. The taperaids in the convergence of the program. Since the geometry dictates that the flux density in any part of the field clamp is less than $0.75 \mathrm{~B}_{\mathrm{O}}$ ' the model used for the computations is a good approximation for $B_{0}<20 \mathrm{kG}$.

\section{EFFECTIVE LENGTH COMPUTATIONS}

The LASL/LBL version of TRIM was used to calculate the vector magnetic potential at each mesh point. It also plots the lines of constant vector potential shown in Figs. 2 and 3 for $B_{0}=11.95 \mathrm{kG}$ and $B_{0}=22.03 \mathrm{kG}$, respectively. The effective length may be calculated directly from the vector potential at the steel yoke on the midplane. The results of the computations are given In Fig. 4 which shows the change in effective length as a function of $\mathrm{B}_{\mathrm{O}}$. Plotted are the measured data ${ }^{1}$ with $0.1 \mathrm{in}$. accuracy and the computation. ${ }^{2}$ It is seen that from 0 to $17 \mathrm{~kg}$ the computation and measurements agree within $0.1 \mathrm{In} .$, which is 1.7 percent of the pole separation.

The difference between computation and measurement in the interval $11<B_{0}<15 \mathrm{kG}$ is probably due to small differences between the 1010 steel excitation characteristic of the actual magnet (annealed at $1300^{\circ} \mathrm{F}$ ) and the characteristic used in the computations (annealed at $1500^{\circ} \mathrm{F}$ ). A TRIM computation was repeated with the correct annealing temperature steel characteristics. The result is marked by an asterisk in Fig. 2 for $B_{0}=11 \mathrm{kG}$ and $\Delta L=2.69 \mathrm{in}$.

III. FRINGE FIELD CORRECTION CONSTANT $k_{1}$ The computed fringe field correction constant ${ }^{3}$ given by

$$
k_{1}=\frac{1}{B_{0}^{2} G} \int_{-\infty}^{-\infty} B(z)\left[B_{0}-B(z)\right] d z
$$

Is plotted in Fig. 5 vs the central field flux density $B_{0^{*}}$. The $k_{1}$ value at $B_{0}=79196$ as obtained from the measured data agrees with the computations to $1-k_{\text {measure }} / k_{\text {computed }}=0.56 \%$. 


\section{References}

1. R. J. Larf, "The Magnet1c Measurements of the Beam Transport Magnets in Use at the Zero Gradient Synchrotron," Argonne National Laboratory, Accelerator Division, Internal Report RJL-8, .July 28, 1967, p. 47.

2. H. F. Voge1, "Computations of Magnet End-Fields," Los Alamos Scientific Laboratory, Internal Report MP-7-23, December 31, 1970.
3. K. L. Brown, "A First and Second-Order Matrix Theory for the Design of Beam Transport Systems and Charged Particle Spectrometers," Stanford Linear Accelerator Center, SLAC-75, p. 74.

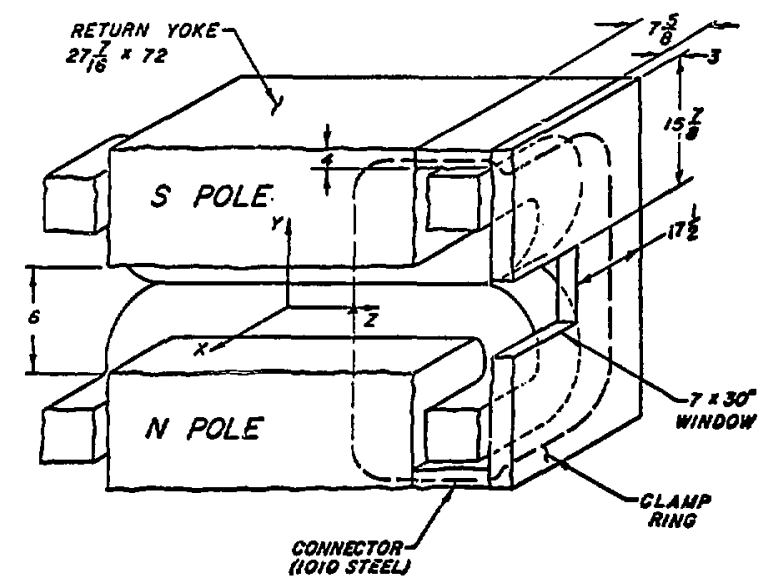

F1g. 1. BM-111 Magaet Geometry.

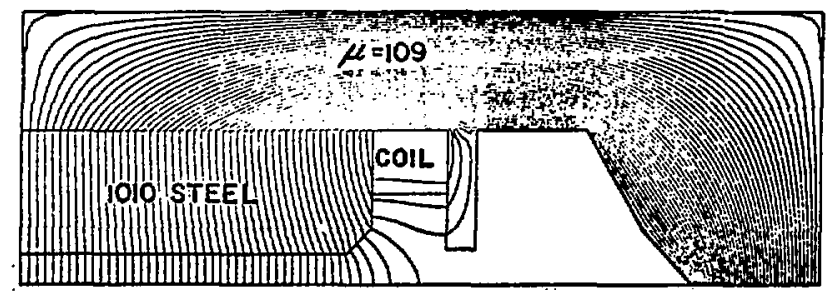

Fig. 2. Flux Plot for $B_{0}=11.95 \mathrm{k} G$.

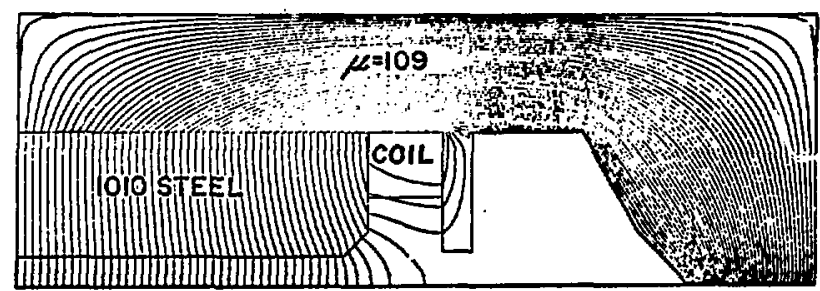

F1g. 3. F1ux Plot for $B_{0}=22.03 \mathrm{kG}$. 


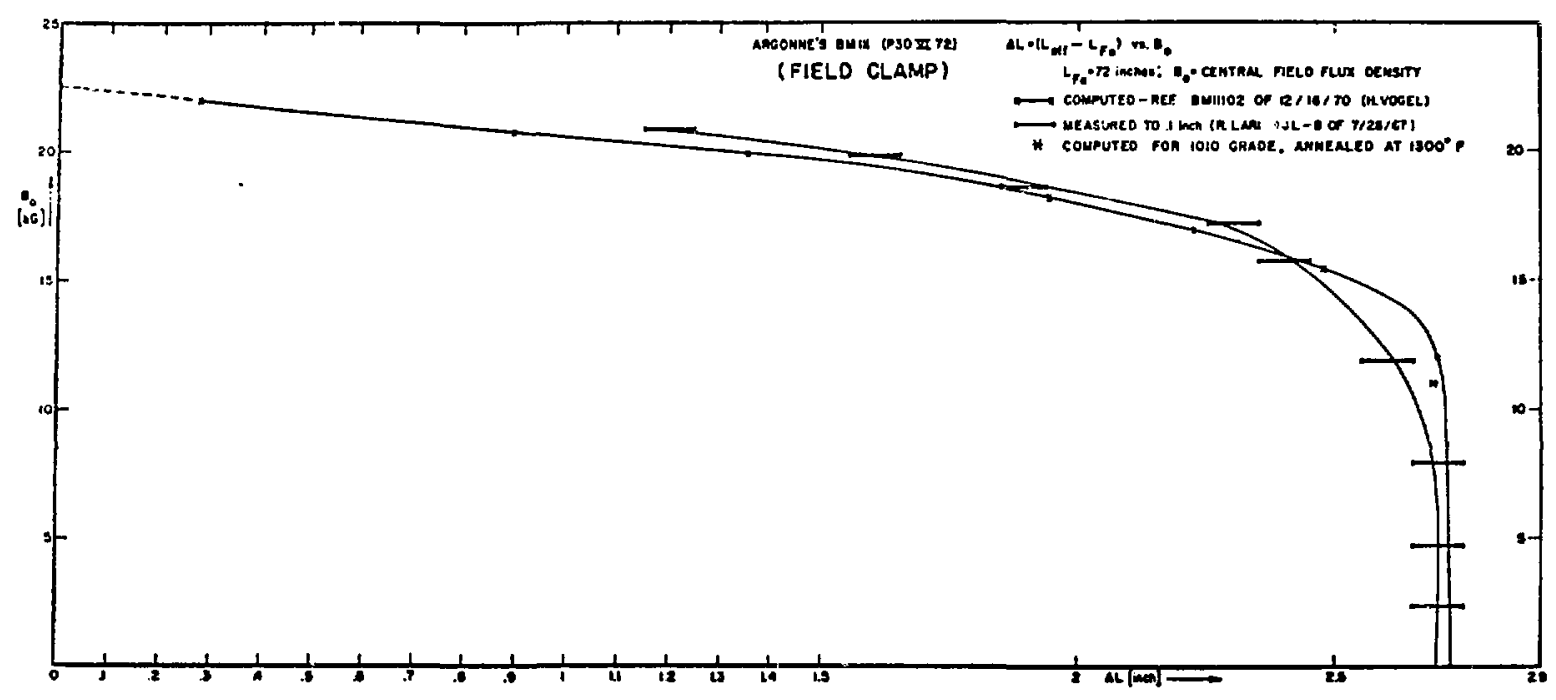

Fig. 4. $B_{0}$ ys $\Delta l$ effective

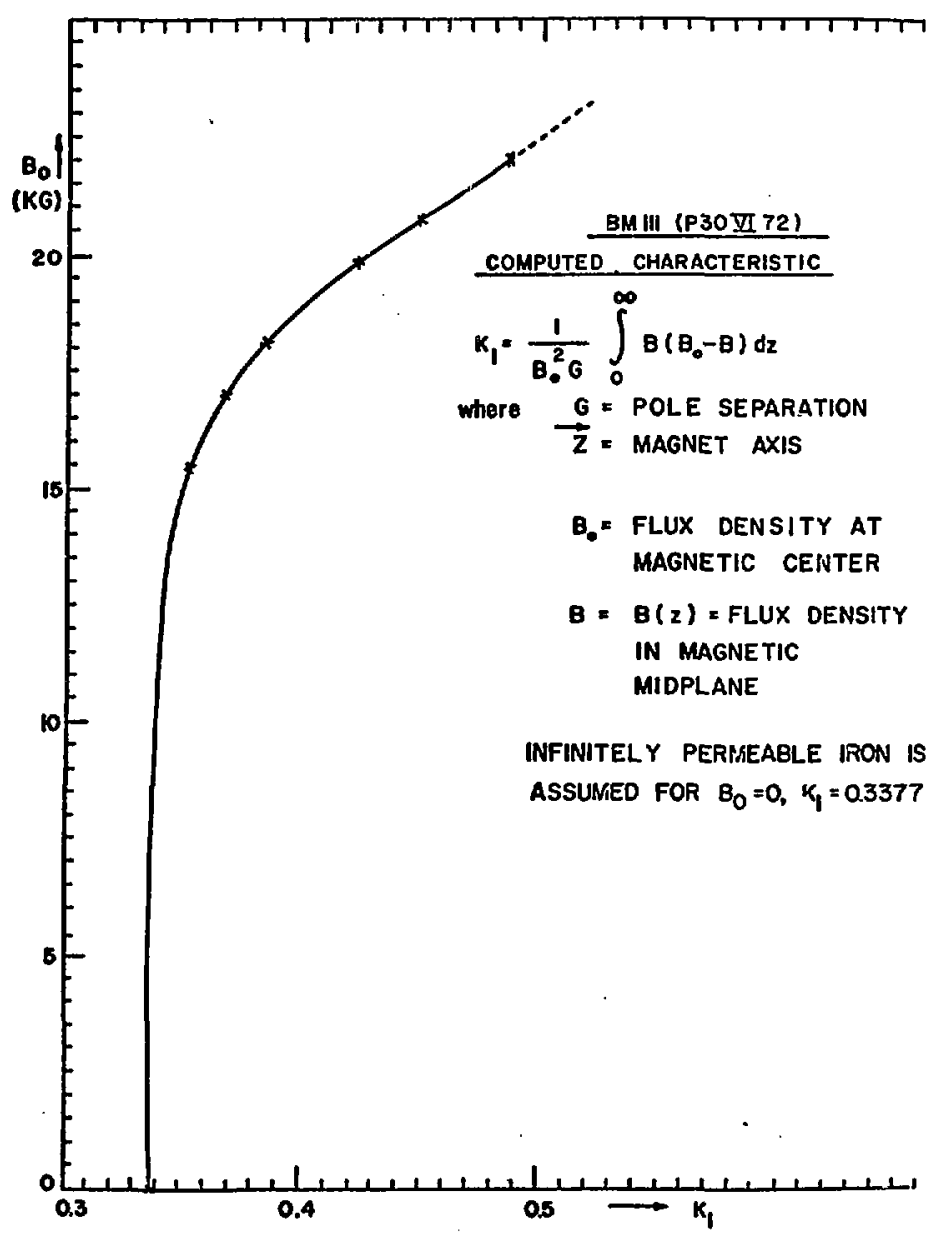

Fig. 5. B v8 $k_{1}$. 